\title{
RISK FACTORS FOR NECROTIZING ENTEROCOLITIS
}

\section{BACKGROUND AND AIMS}

Necrotizing enterocolitis (NEC) in very low birth weight (VLBW) infants has been associated with significant mortality and increased length stay and hospital costs.

Aims: To determine risk or protective factors for the development of necrotizing enterocolitis in VLBW infants.

\section{METHODS}

Retrospective case-cohort study of VLBW infants hospitalized in a Neonatal Intensive Care Unit during 2005-2017 (13 years). Infants with confirmed diagnosis of NEC were evaluated and compared with a cohort without NEC. Statistical analysis included unadjusted and multivariable analyses. Congenital malformations were excluded. Statistical analysis was performed using the SPSS package.

\section{RESULTS}

A total of 592 VLBW infants were admitted; 29 (4.8\%) infants developed NEC.

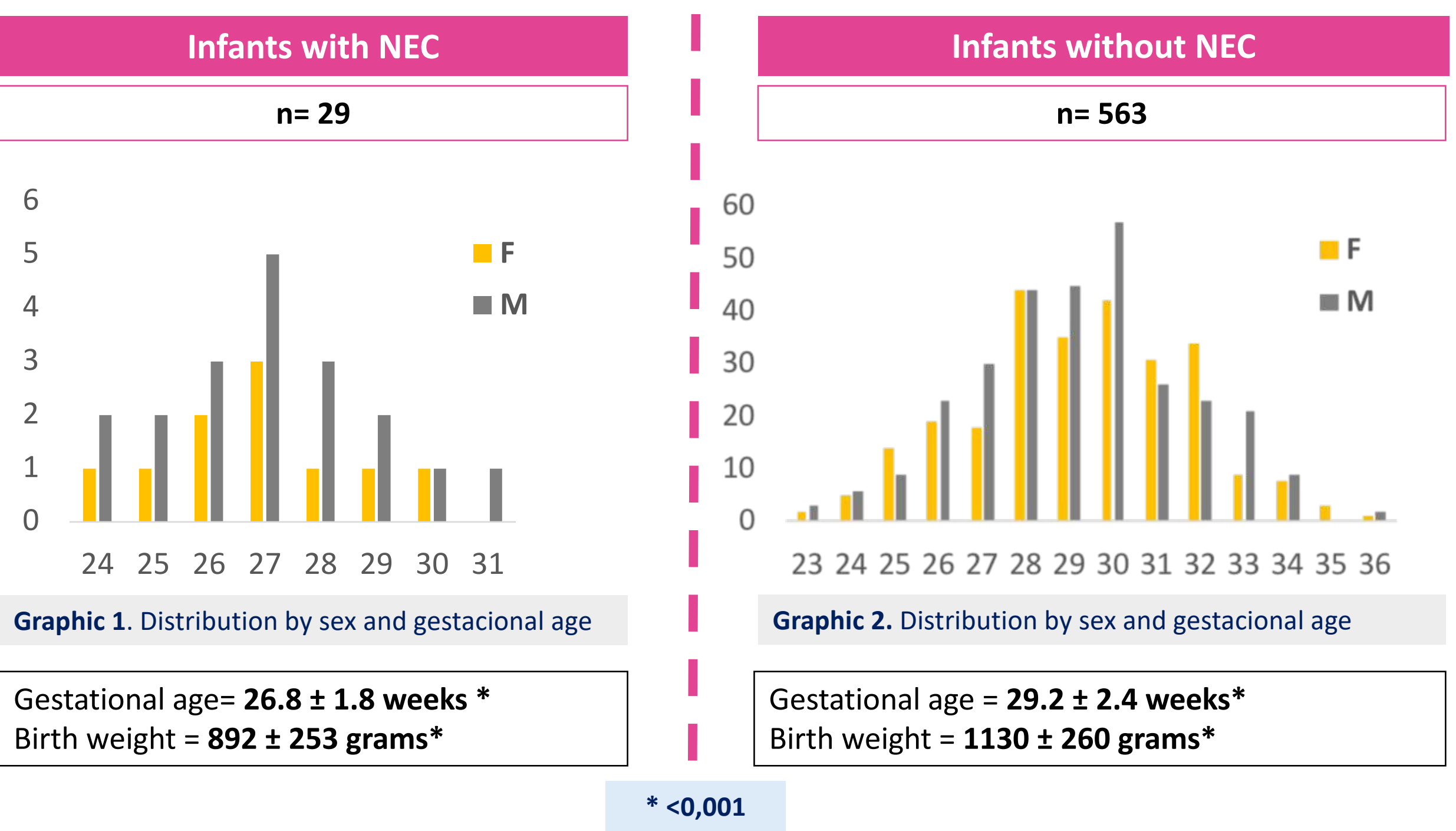

Table 1. Positive blood culture (n)

\begin{tabular}{ll} 
Coagulase-positive staphylococci (13) & Streptococcus agalactiae (3) \\
\hline E. Coli (9) & Candida (2) \\
\hline Enterococcus faecalis ( 5) & Pseudomona aeruginosa (1)
\end{tabular}

\section{RESULTS}

Table 2. Other risk and protective factors for NEC

\begin{tabular}{|c|c|c|c|}
\hline & $\begin{array}{r}\text { INFANTS WITH NEC } \\
(n=29)\end{array}$ & $\begin{array}{l}\text { INFANTS WITHOUT NEC } \\
\qquad(\mathrm{n}=563)\end{array}$ & $\mathbf{p}$ \\
\hline Twin pregnancy, n (\%) & $9(31.0)$ & $166(29.5)$ & NS \\
\hline Changes in uterine blood flow during pregnancy, $n$ (\%) & $6(20.7)$ & $132(23.4)$ & NS \\
\hline Pre-eclampsia, n (\%) & $8(27.6)$ & $162(28.8)$ & NS \\
\hline Gestacional diabetes, $\mathrm{n}(\%)$ & $2(6.9)$ & $37(6.6)$ & NS \\
\hline Prenatal corticosteroids, $\mathrm{n}(\%)$ & $15(71.4)$ & $373(86.9)$ & NS \\
\hline Small for gestational age, $n$ (\%) & $6(20.7)$ & $156(27.7)$ & NS \\
\hline Intubation in the delivery room, $\mathrm{n}(\%)$ & $15(51.7)$ & $167(29.7)$ & 0.012 \\
\hline CRIB > 5, n (\%) & $10(34.5)$ & 95 (16.9) & 0.001 \\
\hline Mechanical ventilation > 7days, $n$ (\%) & $11(11.9)$ & $43(7.6)$ & $<0.001$ \\
\hline Surfactant therapy, $n(\%)$ & $16(55.2)$ & $212(37.7)$ & NS \\
\hline Antibiotic therapy on day one, $n$ (\%) & 27 (93.1) & $369(65.5)$ & 0.001 \\
\hline Red cell transfusion, $n(\%)$ & $17(58.6)$ & $126(22.4)$ & $<0.01$ \\
\hline Pneumothorax, n (\%) & $1(3.4)$ & $16(2.9)$ & NS \\
\hline Hypotension, n (\%) & $14(50.0)$ & $59(10.5)$ & $<0.001$ \\
\hline Patent ductus arteriosus, $\mathrm{n}(\%)$ & $16(59.3)$ & $106(9.1)$ & $<0.001$ \\
\hline Bronchopulmonary dysplasia, $n$ (\%) & $4(23.5)$ & $24(4.8)$ & 0.001 \\
\hline Breast milk, n (\%) & $16(55.2)$ & $486(86.3)$ & $<0.001$ \\
\hline Enteral feeding in the first 3 days, $n(\%)$ & $8(28.6)$ & 344 (63.6) & $<0.001$ \\
\hline
\end{tabular}

Graphic 3. Independents factors for NEC - logistic regression

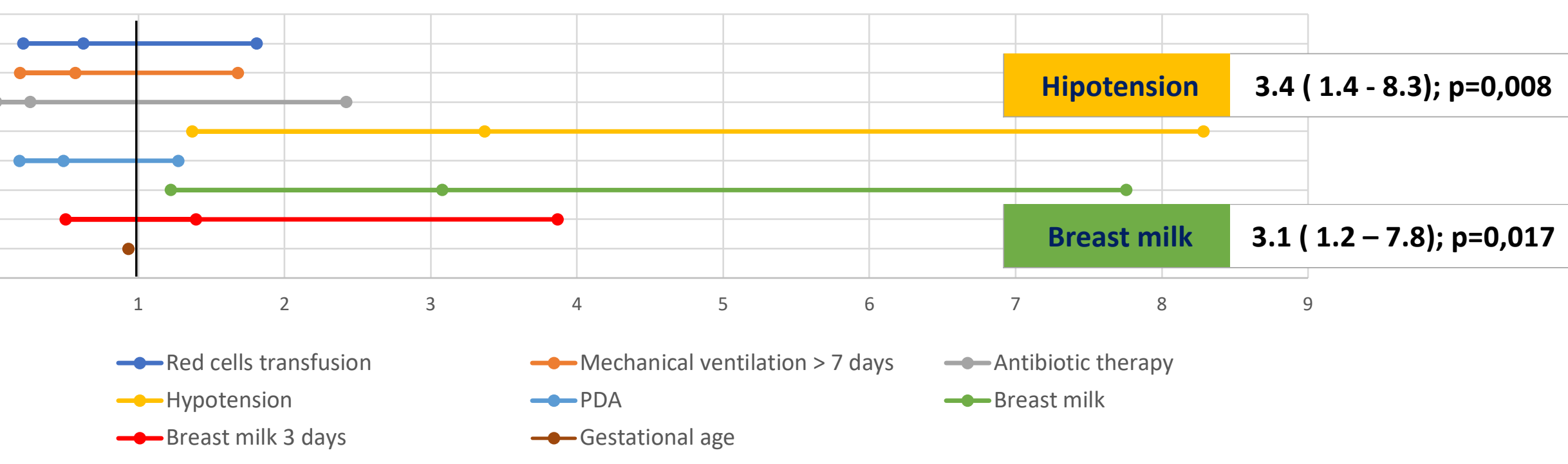

CONCLUSIONS

Breastfeeding should be actively promoted and supported as a key strategy to prevent NEC. 